\title{
Faktor-Faktor Yang Mempengaruhi Keberhasilan UMKM ( Suatu Studi Pada Pedagang Kue di Kecamatan Rumbai Pesisir )
}

\author{
LIVIAWATI, JENI WARDI, GUSMARILA EKA PUTRI \\ Universitas Lancang Kuning \\ Jln. Yos Sudarso Km 08 Rumbai Telp. (0761) 52581 Fax. (0761) 52581 \\ E-mail : watilivia9@gmail.com
}

\begin{abstract}
The establishment of this small, micro and medium-sized business in terms of its establishment is very easy to implement but its sustainability is rather difficult to maintain by its founders. As happened in the Village of Meranti Pandak, Rumbai Pesisir Subdistrict, precisely in RW 13. Where there are dasawisma mothers, whose daily life is baking business. In the course of their business, the women received 2 pieces of cake from the zakat house in 2016 for 10 mothers who had to make cakes for storefront fillers for sale. In addition to providing storefronts, they also provide assistance for mixers, cake boxes, etc. in accordance with what is needed by the mothers in developing their businesses. But zakat houses do not provide assistance in the form of increasing knowledge to these mothers. In the course of time the assistance provided by the zakat house was not maximally utilized where the window used only 1 and the cake-making mothers for the one display window that actively made only 2 people with limited types and variations of cakes available.

In the odd semester ago researchers had carried out community service activities in order to provide knowledge to dasawisma mothers of RW 1, about making cakes from simple and inexpensive ingredients, with various variations and colors. The purpose and purpose of the training was held so that the cake display window could be filled with various kinds of cakes made by the groups of daswisma RW 13 who received assistance from the zakat house and dasawisma mothers RW 1 who wanted to try. In the implementation of community service, many mothers were enthusiastic about learning. However, after the training was carried out out of the many variations of cakes that were taught, researchers only found one type of cake that displayed their cake dietalase and even with less attractive colors. After the researchers did the question and answer who made the cake, it turned out that only one mother made it, and even then who used to make cakes for their storefront fillers. The purpose of this study is to analyze and test the factors that influence the success of UMKM in Rumbai Pesisir District. Data analysis used is descriptive analysis using univariate statistics
\end{abstract}

Keywords: Finance, Commitment, Experience, Business Location, Motivation, Business Capability, UMKM

Usaha mikro,kecil dan menengah ( UMKM ) menjadi pembahasan berbagai pihak bahkan UMKM dianggap penyelamat perekonomian Indonesia di masa krisis pada periode 1998-2000. UMKM adalah usaha kerakyatan yang saat ini mendapat perhatian dan keistimewaan yang diamanatkan oleh undang-undang antara lain bantuan kredit usaha dengan bunga rendah, kemudahan persyaratan izin usaha bantuan pengembangan usaha dari lembaga pemerintah serta beberapa kemudahan lainnya. Bidang-bidang UMKM beragam mulai dari fashion, kuliner, kerajinan hingga pertanian. UMKM ini mempunyai ciri khas yaitu modal yang kecil, resiko yang sedikit tinggi tetapi return juga tinggi dan membawa kewirausahaan bagi pemiliknya. UMKM ini menjadi perhatian pemerintah dengan dibuatnya sebuah kementerian digabung dengan koperasi yang selama ini diperjuangkan, agar bisa tetap hidup karena merupakan cita-cita yang telah diinginkan. Krisis ekonomi yang melanda Indonesia akibat pengaruh melemahnya nilai rupiah tidak dapat terlepas dari kesalahan konsepsi pembangunan ekonomi masa lalu. Kebijakan yang berorientasi pada pengembangan usaha skala besar justru 
semakin melemahkan tatanan ekonomi nasional. Ketergantungan usaha besar pada komponen impor dan modal asing menyebabkan mereka rentan terhadap fluktuasi nilai tukar.

Usaha mikro kecil dan menengah ( UMKM ) menjadi satu pendorong penting dalam membangun kekuatan ekonomi negara. Hal ini dapat dicermati dari keuanggulan UMKM yakni : 1. Cukup feksibel dan sangat mudah beradaptasi dengan pasang surut dan arah permintaan pasar, 2. Menciptakan lapangan kerja yang lebih cepat dibandingkan dengan sektor bisnis lainnya, 3. Memiliki diversiasi yang luas sehingga mampu berkontribusi signifikasi dalam ekspor dan perdagangan.

Jumlah UMKM di indonesia berdasarkan data badan pusat statistik tahun 2016 adalah 56,5 juta. Jika satu UMKM ini memiliki tenaga kerja 1 orang saja maka jumlah tenaga kerja yang bisa diserapnya adalah 56,5 juta orang. Bayang jika UMKM ini bisa menyerap lebih dari satu orang tenaga kerja maka bisa kita bayang sudah berapa banyak yang diserapnya tenaga kerja, dan angka pengangguran pun akan bisa ditekan oleh pemerintah.

Menurut gubernur bank indonesia agus Martowardojo, tercatat, dalam lima tahun terakhir, kontribusi sektor UMKM terhadap PDB dari $75,84 \%$ menjadi $60,34 \%$. Penyerapan tenaga kerja dari sektor tersebut juga tumbuh dari $96,99 \%$ menjadi $97,22 \%$. Selain sumbangsihnya yang cukup besar, agus menilai UMKM adalah sektor yang memiliki ketahanan ekonomi tinggi sehingga mampu bertahan ditengah kondisi yang tidak stabil sekalipun. UMKM dipercaya memiliki ketahanan ekonomi atau resiliensi yang tinggi, sehingga dapat menjadi penopang bagi stabilitas sistem keuangan dan perekonomian.

Pendirian usaha kecil,mikro dan menengah ini dalam hal pendiriannya sangat mudah sekali dilaksanakan akan tetapi keberlangsungannya agak susah dipertahankan oleh para pendirinya. Seperti halnya yang tejadi pada kelurahan meranti pandak kecamatan rumbau pesisir tepatnya pada RW 13. Dimana ada sekelompok ibu-ibu rumah tangga yang tergabung kedalam wadah ibu-ibu dasawisma, yang kesehariannya memiliki usaha pembuatan kue. Kue yang dibuat ibu-ibu itu dititipkan di toko-toko dan kedai-kedai yang ada dijalan sekolah. Dalam perjalanan usahanya, ibu-ibu itu pada tahun 2016 mendapat bantuan etalase kue oleh rumah zakat sebanyak 2 buah dengan pembagian sebagai berikut : 1 etalase diperuntukkan untuk 5 orang ibu-ibu jadi kalau ada 2 berarti ada 10 orang ibu-ibu yang harus membuat kue untuk pengisi etalase buat dijual. Rumah zakat selain memberi bantuan etalase juga memberikan bantuan mixer, kotak kue dll sesuai dengan apa yang dibutuhkan oleh ibu-ibu tersebut dalam pengembangan usahanya. Namun rumah zakat tidak memberikan bantuan berupa peningkatan pengetahuan kepada ibu-ibu tersebut. Seiring perjalanan waktu bantuan yang diberikan oleh rumah zakat tersebut tidak termanfaatkan secara maksimal dimana etalase yang termanfaatkan hanya 1 orang dan ibu-ibu pembuat kue untuk etalase 1 buah itu yang aktif membuat hanya 2 orang dengan keterbatasan jenis dan variasi kue yang ada.

Pada semester ganjil yang lalu peneliti pernah melakukan kegiatan pengabdian masyarakat dalam rangka memberikan pengetahuan kepada ibu-ibu yang tergabung kedalam kelompok itu dan ibu-ibu dasawisma RW 1, tentang membuat kue dari bahan-bahan sederhana dan murah, dengan berbagai variasi dan warna. Maksud dan tujuan pelatihan itu diadakan adalah agar etalase kue itu bisa berisi dengan macam-macam kue hasil buatan kelompok ibu-ibu dasawisma RW 13 yang mendapat bantuan dari rumah zakat dan ibu-ibu dasawisma RW 1 yang mau berusaha. Pada pelaksanaan pengabdian masyarakat itu banyak ibu-ibu yang antusias belajar. Akan tetapi setelah pelatihan dilaksanakan dari sekian banyak variasi kue yang diajarkan, peneliti hanya menjumpai satu jenis kue aja yang

p.ISSN: $2407-800 X \quad$ e.ISSN: 2541-4356 
terpajang dietalase kue mereka itupun dengan warna yang kurang menarik. Setelah peneliti tanya siapa yang membuat kue itu ternyata hanya 1 orang ibu yang buat itupun yang biasa buat kue untuk pengisi etalase mereka. Berdasarkan latarbelakang masalah yang diutarakan diatas maka kami tertarik untuk melakukan penelitian yang berjudul faktor-faktor yang mempengaruhi keberhasilan UMKM ( suatu studi pada pedagang kue dikecamatan rumbai pesisir )

Penelitian tentang faktor-faktor yang mempengaruhi keberhasilan UMKM telah banyak diteliti oleh peneliti terdahulu yaitu penelitian hartono dan deni dwi hartono yang berjudul Faktor-faktor yang mempengaruhi perkembangan UMKM di Surakarta, dimana hasil penelitiannya menunjukkan bahwa biaya modal berpengaruh signifikan terhadap perkembangan bisnisnya, sedangkan umur dan lama beroperasinya perusahaan tidak berpengaruh siginifikan terhadap perkembangan bisnisnya. Analisis faktorfaktor yang mempengaruhi keberhasilan usaha kecil dan menengah pada pengrajin tenun songket didesa jinengdalem kecamatan buleleng ( Nimade Diah anggraeni ), dimana faktor yang diteliti adalah faktor motivasi,usia, pengalaman dan,pendidikan. Hasil penelitiannya adalah faktor motivasi berpengaruh terhadap keberhasilan usaha kecil dan menengah didesa jinengdalem kecamatan buleleng. Serta Analisis faktor-faktor yang mempengaruhi keberhasilan usaha kecil ( studi kasus pada usaha laundry mikro kecil dilingkungan sekitar kampus USU ). Pada penelitian ini terdapat 3 faktor yang dianalisis yaitu faktor pengetahuan kewirausahaan, strategi pemasaran,dan manajemen permodalan keuangan. Hasil penelitian yang diperoleh oleh peneliti adalah ketiga faktor tersebut berpengaruh terhadap keberhasilan usaha laundry dilingkungan sekitar kampus USU ( kaban, christo ).
MKM menurut pendapat longenecker, moore dan petty ( 2001 ) adalah bisnis yang memiliki kriteria :

1) Bisnis tersebut disediakan oleh satu orang atau sekelompok kecil orang.Hanya dalam situasi tertentu saja sebuah bisnis memiliki 15 orang pemilik

2) Kecuali fungsi pemasaran, operasi bisnis tersebut dilakukan disatu tempat.

3) Bila dibandingkan dengan perusahaan tersebsar di industri tersebut,perusahaan ini termasuk kecil.

4) Jumlah karyawan pada perusahaan tersbut kurang dari 10 orang

Faktor-faktor yang mempengaruhi keberhasilan Menurut storey dalam longeneckerg keberhasilan atau kegagalan dalam berwirausaha dipengaruhi oleh karakteristik pengusaha : umur,jenis kelamin, pengalaman kerja, pendidikan, sikap dan mental pengusaha.

Karakteristik dari usaha kecil menengah : Asal perusahaan, lama waktu beroperasi,ukuran usaha,sumber modal dan lokasi

Variabel konstektual : adalah halhal atau aktivitas yang berada disekitar usaha dimana dapat mempengaruhi perusahaan dan juga hal-hal atau aktivitas yang terkait dengan perusahaan atau dilakukan oleh perusahaan seperti pemasaran, tehnologi, akses informasi, legalitas, akses modal. Dukungan pemerintah, rencana bisnis, tim manajemen, persaingan dan inovasi. Menurut basrowi ( 2011 ), faktor yang mempengaruhi keberhasilan usaha adalah motivasi, Usia, pengalam dan pendidikan

Suryana (2011) melihat keberhasilan usaha dari bagaimana bisnis dalam mencapai tujuannya. Suyanti ( 2010) menyatakan kinerja usaha perusahaan menjadi salah satu tujuan pengusaha. Kinerja usaha didefinisikan sebagai tingkat keberhasilan dalam pencapaian tujuan yang diharapkan.

p.ISSN: $2407-800 X \quad$ e.ISSN: 2541-4356 
Dengan pendapat tersebut, dapat disimpulkan bahwa suatu usaha dikatakan berhasil apabila memiliki suatu kelebihan dibandingkan dengan periode sebelumnya atau dengan perusahaan sekelasnya. Suatu usaha dikatakan berhasil jika memperoleh laba meski laba bukan meupakan satusatunya aspek yang dinilai dari keberhasilan sebuah usaha.

Menurut teori Ir. Hendro,.MM, keberhasilan suatu usaha dipengaruhi oleh komitmen, pengalaman, keuangan, lokasi usaha, motivasi dan kemampuan usaha ( hendro, 2011, dasar-dasar kewirausahaan panduan bagi mahasiswa untuk mengenal, memahami dan memasuki dunia Bisnis, Erlangga, jakarta)

\section{METODE}

Objek penelitian ini ialah Faktorfaktor yang mempengaruhi keberhasilan usaha kecil sedangkan populasi yang digunakan dalam penelitian ini adalah semua pedang kue yang berada dikecamatan rumbai pesisir, yang berjumlah 20 0rang

Sampel yang digunakan dalam penelitian adalah 15 orang saja dengan menggunakan tehnik random sampling

Data yang digunakan dalam penelitian ini diambil dengan menggunakan tehnik random sampling.

Untuk menganalisis data penelitian ini digunakan analisa deskriptif. Analisis deskriptif adalah analisis data dengan menggunakan statistik-statistik univariate seperti rata-rata, median, modus, deviasi standar dan varians.Analisis deskriptif ini digunakan untuk mendeskripsikan suatu keadaan atau gejala atau persoalan agar mudah penarikan kesimpulan. Pada statistik deskriptif hanya ditujukan pada sekumpulan data yang ada. Statistik deskriptif merupakan alat analisis untuk menjelaskan, meringkas mereduksi, menyederhanakan, mengorganisasi dan menyajikan data ke dalam bentuk yang teratur sehingga mudah dibaca, dipahami dan disimpulkan (Wiyono,2001)

\section{HASIL}

Koesioner

yang dikumpulkan dari responden setelah ditabulasi jawabannnya ( lampiran 1 ) maka dapat dijelaskan sebagai berikut :

1. Keuangan, Pada umumnya pedagang dikecamatan rumbai pesisir ini awal pembukaan usahanya menggunakan modal sendiri, akan tetapi mereka tidak membuat pencatatan terhadap peredaran usahanya. Selama menjalankan usaha mereka kadang mengalami kesulitan keuangan akan tetapi sebagian besar tidak mau meminjam dana kepada koperasi-koperasi yang gelap tersebut.

2. Motivasi, Pada umumnya pedagang dikecamatan rumbai pesisir ini berdagang karna untuk memenuhi kebutuhan hidupnya sehingga mau tidak mau mereka harus giat dan tekun berdagang agar semua kebutuhan hidupnya bisa terpenuhi. Hal ini bisa terlihat dari jawaban koesiner motivasi nomor 1,2,5, dan 6 dilampiran 4 . Mereka berdagang bukan karna paksaan.

3. Komitmen, Berdasarkan hasil koesioner pada lampiran 4 terlihat bahwa pedagnag kue dikecamatan rumbai pesisir mempunyai komitmen yang kuat dalam memajukan usahanya karena mereka sadar bahwa usaha kue mereka ini bertujuan untuk memenuhi kebutuhan hidup mereka sehari serta untuk membiayai sekolah anak mereka. Penjual kue dikecamatan rumbai pesisir juga pembuat kue. Walaupun sejak tahun 2017 penjualan agak menurun tapi pedagang kue tetap berdagang. Mereka tidak kehilangan semangat berdagang, karena berdagang adalah kehidupan mereka. 
4. Pengalaman, Para pedagang kue dikecamatan rumbai pesisir ada yang memiliki pengalaman dagang dari kecil. Mereka terlahir pada keluarga pedagang. Jadi mereka berdagang bukan secara tiba-tiba. Akan tetapi ada juga pedagang kue itu berdagang tanpa pengalaman misalnya mereka terpaksa dagang karena suami mereka di phk.

5. Lokasi dagang, Kata pedagang, lokasi dagang sangat menentukan. Berdasarkan hasil koesioner pada lampiran 4 bagian lokasi dagang, kadang-kadang pedagang terpaksa berpindah-pindah untuk menentukan lokasi yang pas. Jika suatu lokasi sudah mereka coba namun sepi pembeli mereka akan mencari tempat yang baru Cuma lagi kadang-kadang berbenturan dengan pemilik toko, maksudnya kebanyakan pedagang dikecamatan rumbai pesisir< berdagang didepan toko orang lain kadang-kadang si pemilik toko tidak mengijinkan mereka berdagang didepan toko mereka dengan alasan tertutupi toko mereka dibelakang, kalau hal ini terjadi terpaksa pedagang kue itu pindah.

6. Kemampuan usaha, Pedagang kue yang ada dikecamatan meranti pandak menjual kue yang mereka buat sendiri dan kue titipan orang lain, dalam menghitung harga pokok kue yang mereka buat, mereka belum akurat, kebanyakan pedagang hanya mahir memasarkan kue yang mereka jual.

\section{Pengujian Hipotesis}

\begin{tabular}{|c|c|c|c|c|c|c|}
\hline \multirow{2}{*}{\multicolumn{2}{|c|}{ Model }} & \multicolumn{2}{|c|}{ Unstandardized Coefficients } & \multirow{2}{*}{$\begin{array}{c}\text { Standardized Coefficients } \\
\text { Beta }\end{array}$} & \multirow[b]{2}{*}{ t } & \multirow[b]{2}{*}{ Sig. } \\
\hline & & $B$ & Std. Error & & & \\
\hline 1 & (Constant) & 4.015 & 1.935 & & 2.075 & .072 \\
\hline & Keuangan & -.585 & .265 & -183 & -2.205 & .058 \\
\hline & Motivasi & -241 & .214 & -.136 & -1.127 & 292 \\
\hline & Komitmen & -058 & 105 & -.055 & -.552 & .596 \\
\hline & Pengalaman & .049 & 207 & .059 & .239 & .817 \\
\hline & Lokasi Usaha & .904 & .186 & .750 & 4.853 & .001 \\
\hline & $\begin{array}{l}\text { Kemampuan } \\
\text { Usaha }\end{array}$ & .452 & .294 & .331 & 1.536 & .163 \\
\hline
\end{tabular}

Berdasarkan hasil olahan data diatas terlihat bahwa hanya 2 variabel yang berpengaruh dalam keberhasilan pedagang kecil dikecamatan meranti pandak yaitu keuangan dan lokasi usaha.

$$
\begin{gathered}
\text { Tabel 5.2. } \\
\text { Hasil uji simultan }
\end{gathered}
$$

\begin{tabular}{|l|r|r|r|r|r|}
\hline Model & \multicolumn{1}{|c|}{$\mathrm{R}$} & R Square & $\begin{array}{c}\text { Adjusted R } \\
\text { Square }\end{array}$ & $\begin{array}{c}\text { Std. Error of the } \\
\text { Estimate }\end{array}$ & Durbin-Watson \\
\hline 1 & $.990^{\mathrm{a}}$ & .980 & .964 & .62459 & 1.968 \\
\hline
\end{tabular}

Sumber: Hasil Olahan Data

Berdasarkan hasil uji simultan pada tabel diatas dapat dikatakan bahwa pengaruh variabel keuangan, motivasi,komitmen,pengalam usaha, kemampuan usaha dan lokasi usaha secara bersama - sama mempengaruhi keberhasil usaha pedagang kecil dikecamatan rumbai pesisir dimana pengaruh keenam variabel tersebut sebesar $98 \%$ sedangkan $2 \%$ dipengaruhi oleh faktor lain diluar dari variabel yang peneliti teliti.

\section{PEMBAHASAN}

Keberhasilan pedagang kecil dalam usahanya dipengaruhi oleh beberapa faktor diantara adalah faktor keuangan, motivasi,komitmen,pengalaman,kemapuan usaha dan lokasi usaha akan tetapi dari keenam faktor tersebut ada beberapa faktor yang paling kuat pengaruhnya kepada berhasilan usaha yaitu faktor keuangan dan lokasi usaha.

Faktor keuangan adalah faktor yang penting dalam keberhasilan usaha, yang dimaksud faktor keuangan disini adalah moda, kemampuan mengelola modal dan kemampuan melakukan pencatatan terhadap setiap aktifitas keuangan. Pengelolaan keuangan ini merupakan faktor yang sangat penting dalam hal keberlanjutan usaha, sering sekali suatu 
usaha kecil gulung tikar gara-gara faktor keuangan ini. Pada faktor keuangan ini si pemilik usaha dituntut harus mahir mengelola keuangan, sebaiknya pemilik usaha memiliki pencatatan sederhana sehingga sepemilik mengetahui apakah usaha mereka mengalami peningkatan penjualan atau tidak, berlaba atau tidak dan seberapa besar laba yang mereka terima setiap harinya. Mengetahui berapa besar laba yang mereka terima setiap harinya penting sekali biar bisa memperhitungkan berapa uang yang bisa mereka pakai untuk keperluan sehari-hari supaya jangan sampai modal dagangan terpakai untuk memenuhi kebutuhan seharihari.

Selain faktor keuangan, ada faktor lain yang tidak kalah penting dengan faktor keuangan ini yang menentukan keberhasil usaha kecil yaitu faktor lokasi usaha, Lokasi usaha harusla yang benar-benar tepat maksudnya lokasi usaha harus tepat sesuai dengan jenis dagangan yang diperjual belikan, contonya pedagang kue sebaiknya berdagang kue berlokasi di area sekolah yang banyak anak-anak dan rumah tangga. Jika pedagang kue berjualan dilokasi yang banyak anak-anak maka sebaiknya harga kue yang mereka jual harus sesuai dengan kantong anak-anak pula misalnya kue yang mereka jual harga Rp 500 sampai Rp 1000.

\section{SIMPULAN}

Berdasarkan hasil penelitian diatas maka peneliti menyimpulkan : Pedagang kecil ( kue ) dikecamatan meranti dalam berdagang mengandalkan modal sendiri, memiliki motivasi yang kuat serta komitmen yang kuat dalam berusaha dan Hasil uji regresi diatas menyimpulkan bahwa ada 2 faktor yang mempengaruhi keberhasilan pedagang kecil yaitu faktor keuangan dan faktor lokasi usaha.

\section{DAFTAR RUJUKAN}

Departemen Koperasi Dan Usaha Mikro Kecil Dan Menengah, UU no 20 tahun 2008 tentang UMKM, http://www.depkop.go.id
Basrowi,2011. Kewirausahaan untuk perguruan tinggi, bogor, PT ghalia indonesia

Hendro, 2011, dasar-dasar kewirausahaan panduan bagi mahasiswa untuk mengenal, memahami dan memasuki dunia Bisnis, Erlangga, jakarta

Hartono, Faktor-faktor yang mempengaruhi perkembangan UMKM di Surakarta, https://ejournal .uns.ac.id

Kaban,cristo, . Analisis faktor-faktor yang mempengaruhi keberhasilan usaha kecil ( studi kasus pada usaha laundry mikro kecil dilingkungan sekitar kampus USU ), https://respository.usu.ac.id

Longeneckerg, kewirausahaan manajemen usaha kecil,2001, salemba empat, Jakarta

Nimade diah anggraeni, Analisis faktorfaktor yang mempengaruhi keberhasilan usaha kecil dan menengah pada pengrajin tenun songket didesa jinengdalem kecamatan buleleng, https://ejournal.undiksha.ac.id

Suryana, 2011, kewirausahaan . jakarta . Salemba Empat 